\title{
Bimodal actions of selenium essential for antioxidant and toxic pro-oxidant activities: The selenium paradox (Review)
}

\author{
KYUNG HEE LEE and DAEWON JEONG
}

\begin{abstract}
Department of Microbiology and Aging-Associated Vascular Disease Research Center, Yeungnam University College of Medicine, Daegu 705-717, Republic of Korea
\end{abstract}

Received August 20, 2011; Accepted October 25, 2011

DOI: $10.3892 / \mathrm{mmr} .2011 .651$

\begin{abstract}
Selenium is an essential biological trace element. Adult daily intake of selenium should be approximately $100 \mu \mathrm{g}$ per day. This compound has a two-sided effect depending on its concentration. A selenium-deficient diet is associated with various endemic diseases, including cardiomuscular malfunctions, osteoarthritis, cancer and viral infections that lead to premature death. These defects are prevented when dietary intake of selenium is adequate. The preventive biological effect of selenium is considered to be due to the antioxidant function of selenoproteins with a selenocysteine in the active site of the catalytic domain. Antioxidant selenoproteins maintain the intracellular redox status and, as a result, normal physiological processes in the cell. Conversely, an overdose of selenium generates oxygen radicals and leads to apoptotic cell death by inducing oxidation and cross-linking of protein thiol groups essential for cell survival. A lower redox state caused by selenium may be implicated in toxic diseases, such as alkali disease and blind staggers. Collectively, selenium seems to have both harmful and beneficial attributes. The aim of this review is to summarize the various biological functions of selenium and to illustrate its opposite roles as a pro-oxidant and an antioxidant.
\end{abstract}

\section{Contents}

1. Introduction

2. Selenium status and its biological actions

3. Selenium-induced thiol oxidation and ROS generation

4. Selenium-induced apoptosis

5. Biological functions of selenium-containing antioxidant proteins

6. Conclusions

Correspondence to: Dr Daewon Jeong, Department of Microbiology and Aging-Associated Vascular Disease Research Center, Yeungnam University College of Medicine, 317-1 Daemyung-Dong, Nam-Gu, Daegu 705-717, Republic of Korea

E-mail: dwjeong@ynu.ac.kr

Key words: antioxidant, apoptosis, oxidative stress, selenium, selenoprotein

\section{Introduction}

Most essential micronutrients appear to play opposing roles in biological processes depending on their concentrations. While adequate dietary micronutrient intake is beneficial, deficient or excessive intake often leads to biological malfunctions resulting in the development of a wide diversity of diseases. Selenium, an essential micronutrient, recycles through the food chain and its concentration at each stage is basically determined by the amount remaining in the soil (1). The geographic distribution of selenium varies widely from selenium-deficient to selenium-rich regions $(2,3)$. As with most essential micronutrients, selenium exhibits various biological functions according to its intake concentrations. At adequate concentrations, selenium exists as selenocysteine in the catalytic site of antioxidant proteins, including glutathione peroxidase and thioredoxin reductase, and is involved in the regulation of cellular redox status $(4,5)$. However, a deficiency in selenium has been linked to many clinical symptoms including Kashin-Beck disease, which is characterized by bone and joint degeneration in children (6), and Keshan's disease that is known to cause cardiomyopathy in humans (1,7). Moreover, it is well known that an excessive intake of selenium results in toxic symptoms including alkaline disease and blind staggers in livestock $(8,9)$. Selenium poisoning is thought to result from the generation of oxygen radicals that can lead to DNA damage, lipid peroxidation, and premature protein degradation inside the cell (10-12). Selenium concentrations that prevent deficiency symptoms and are sufficient for exerting beneficial effects are close to those that lead to toxicity. Additionally, the safety margin of selenium dosage depends on various factors including age, gender, the chemical form present in the diet, transport capacity through cellular cytoplasmic membranes, efficiency of bioconversion from the inorganic to organic forms as well as exposure duration, frequency, and route. For these reasons, it is difficult to determine the exact safety levels of dietary selenium. Collectively, selenium seems to have bimodal roles in various biological processes. Several questions have been raised about how selenium simultaneously exerts beneficial and harmful effects under different circumstances. This article briefly discusses the diverse dose-dependent biological events associated with selenium and summarizes the biochemical roles of selenium in the regulation of cellular redox status focusing on the dual characteristics of selenium as an antioxidant and a pro-oxidant. 


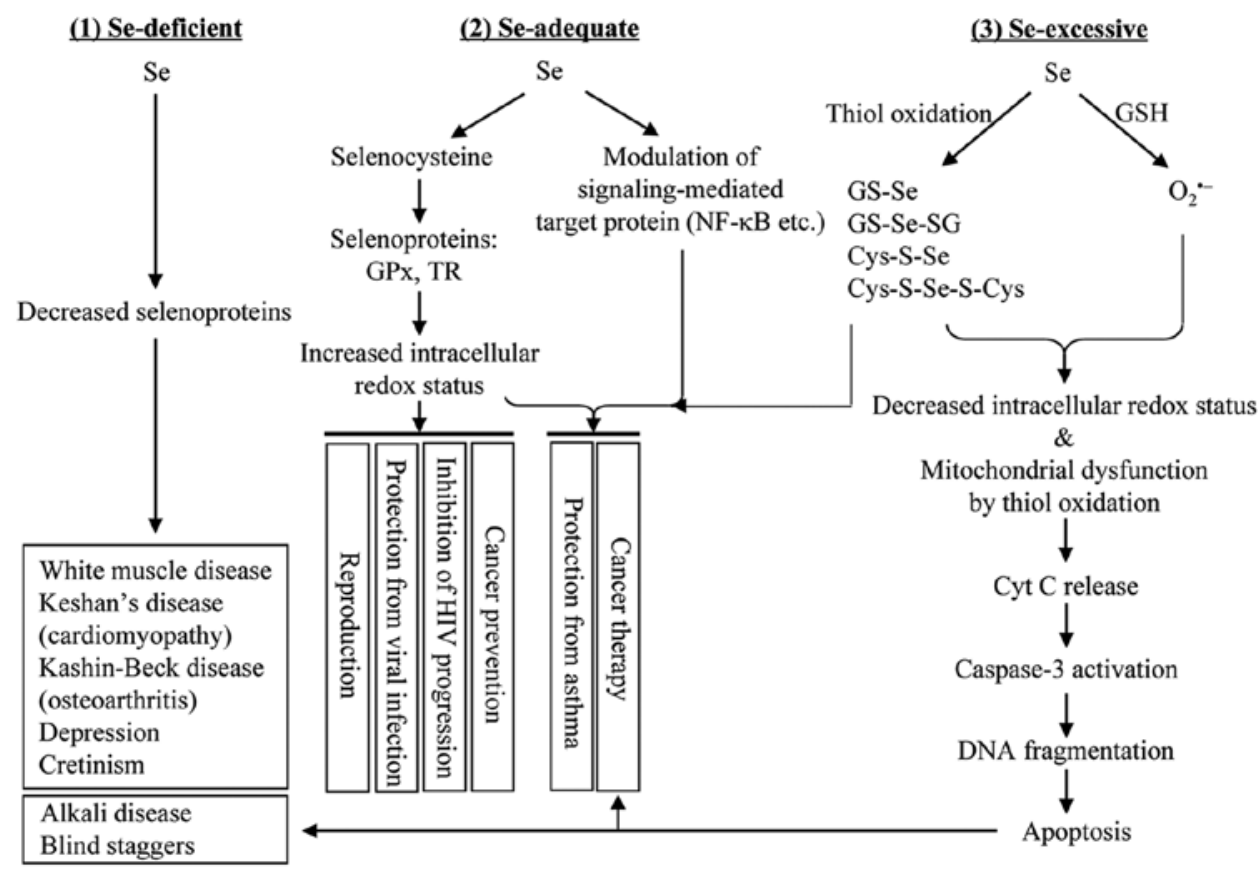

Figure 1. Various biological functions of selenium depending on its intake concentrations. Several clinical symptoms caused by selenium deficiency include white muscle disease, Keshan's disease (cardiomyopathy), Kashin-Beck disease (osteoarthritis), depression, and cretinism. Selenium at physiological levels plays an important role in the cellular redox regulation, existing as selenocysteine at the catalytic site of antioxidant enzymes and inducing intracellular redox potential and thiol modification of the targeted proteins such as NF- $\mathrm{KB}$. High levels of selenium often cause selenium toxicity (termed apoptosis), which results from the generation of oxygen radicals, mitochondrial dysfunction and DNA damage. Se, selenium; GPx, glutathione peroxidase; TR, thioredoxin reductase; $\mathrm{GSH}$, reduced glutathione; Cyt C, cytochrome c.

\section{Selenium status and its biological actions}

The difference in selenium concentrations in food sources depends on its contents in soil. The geographical distribution of selenium ranges from selenium-deficient regions in China, including areas from the northeast to southwest and southeast Siberia $(2,3,13,14)$, to selenium-rich regions in Ireland, Israel, northern Australia and the western US (15). Differences in selenium dietary intake become serious at the top of the ground food chain. The various biological characteristics of selenium depending on concentration are shown in Fig. 1.

Selenium dietary intake less than $10 \mu \mathrm{g}$ /day results in white muscle disease (WMD) in lambs and calves, which is characterized by white-colored tissues due to calcified skeletal and cardiac muscle, and leads to premature death by cardiomuscular dysfunction $(16,17)$. In humans, a cardiomyopathy analogous to WMD, Keshan's diseases, has been reported $(18,19)$. This is an endemic disease among people living in the volcanic regions of China with selenium-deficient soil, and is associated with clinical symptoms, such as heart hyperplasia and failure, in children and women of childbearing age. Additionally, Kashin-Beck disease manifests as osteoarthropathy from epiphyseal degeneration of the arm and leg joints with subsequent growth retardation, and occurs in areas of China, Tibet, and southern Siberia where selenium intake is low among the population (6). Clinical studies have also revealed that selenium deficiency is linked to viral diseases caused by coxsackie $\mathrm{B}$ along with hepatitis $\mathrm{B}$ and $\mathrm{C}$, progression of human immunodeficiency virus (HIV) infection, male subfertility, and high risks of developing cancer, depression, and cretinism (1,20-24).
Adequate selenium intake, approximately $100 \mu \mathrm{g}$ daily in adult humans (20) which does not exceed $1 \mathrm{mg}$, greatly reduces the rates of death from viruses such as coxsackie, hepatitis, and HIV. Moreover, adequate selenium intake reduces the incidence of cancer and is important for male reproduction (22-24). These preventive and protective effects supposedly represent the antioxidant function of selenium-containing selenoproteins. Most of the selenoproteins, such as glutathione peroxidase (GPx), thioredoxin reductase (TR), and methionine-R-sulfoxide reductase 1 (MsrB1), serve as antioxidants $(4,5,25)$. Furthermore, selenium can be used for protection against allergen-induced asthmatic inflammation (26) and cancer therapy (27). This chemopreventive effect is thought to result from the combined actions of the antioxidant functions of selenoproteins and the thiol modification of targeted proteins essential for allergen-mediated signaling pathways and cancer processing. An additional possible mechanism for the anti-carcinogenic effects of selenium is thought to be its cytotoxicity and anti-proliferative effects in malignant cells, due to oxidative stress resulting from thiol oxidation of cellular reductant molecules and oxygen radical production.

Chronic exposure to high doses of dietary selenium in the range of milligrams per kilogram causes alkali diseases and blinder staggers in livestock that graze in pastures with selenium-rich soil $(8,9)$. Since plants absorb selenium more easily when grown in alkali soil, alkali disease frequently occurs in livestock that feed on selenium-tolerant plants with high selenium levels ranging from 5 to 50 milligram per kilogram of mass. Animals with this disease present abnormal symptoms, including hoof malformation, lameness, anemia, and stiffness. Blind staggers is an acute selenium poisoning disease 


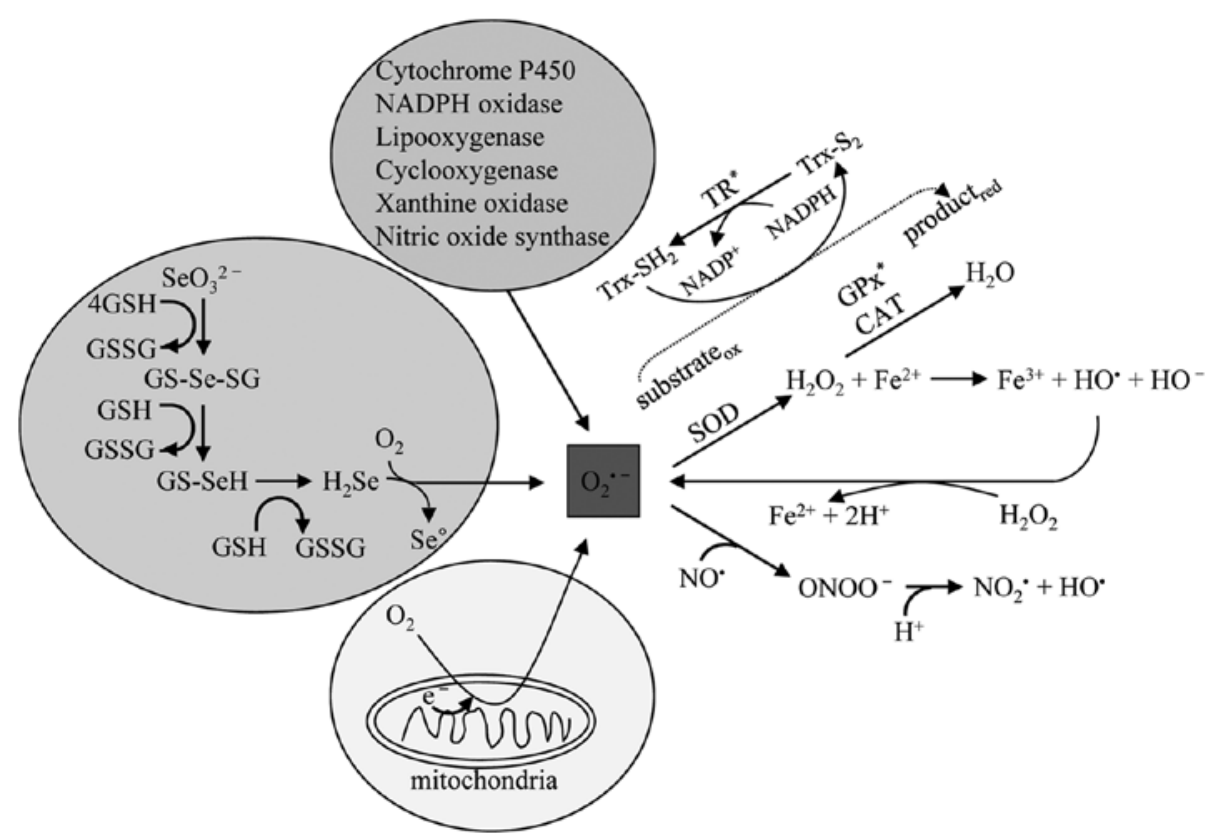

Figure 2. Generation of intracellular oxygen radicals and oxidant scavenging processes. Superoxide anions are produced by many oxidant-generating proteins and mitochondria, and by the reaction of selenium with reduced glutathione (GSH). These are converted into less toxic or non-toxic molecules through the enzymatic activities of antioxidant proteins. A detailed description of these processes is provided in the main text. "Selenium-containing selenoprotein. GPx, glutathione peroxidase; TR, thioredoxin reductase; Trx, thioredoxin; SOD, superoxide dismutases; CAT, catalase; GSSG, oxidized glutathione.

appearing in cows and sheep, and is characterized by altered behavior, impaired vision, weight loss, ataxia, and respiratory failure. Symptoms of human selenium poisoning include loss of hair and nails, tooth decay, dermatitis, and gastroenteritis (28-30). Selenium toxicity develops in mammals with a daily intake of one milligram of selenium per kilogram of body weight, and in cultured cells exposed to micromolar concentrations of selenium (31-33). Selenium toxicity is believed to be a result of low cellular redox status due to the oxidization of protein thiol groups and glutathione, and the generation of oxygen radicals. The toxic mechanism underlying oxidative damage by selenium is discussed in detail in the following section.

\section{Selenium-induced thiol oxidation and ROS generation}

Selenium is capable of negatively affecting cellular redox status by directly oxidizing thiols and indirectly generating reactive oxygen species (ROS), leading to a decreased reduction status in cells and cellular damage. Selenium reacts with essential thiol groups of proteins and cysteine residues of reduced glutathione (GSH) to form an intramolecular disulfide bond, a selenitrisulfide bond (S-Se-S), and a selenenylsulfide bond (S-Se) (34). This can inactivate signaling molecules by oxidizing redox-sensitive cysteine residues present within the enzymatic active site of the catalytic domain. Selenium-induced oxidation of cysteine residues in transcription factors such as NF- $\mathrm{NB}$ and AP-1 leads to reduced binding affinity of these factors to their target DNA sites $(26,35,36)$. Furthermore, other redox-sensitive enzymes shown to be targeted for thiol oxidation by selenium include caspase-3, Cdk2, protein kinase $\mathrm{C}, \mathrm{JNK}, \mathrm{Na}^{+}-\mathrm{K}^{+}$-dependent ATPase, glucocorticoid receptors, prostaglandin D synthase, human squalene monooxygenase, and mitochondrial proteins.
Among these proteins, NF- $\kappa \mathrm{B}, \mathrm{AP}-1$, caspase $-3, \mathrm{Cdk} 2$, protein kinase $\mathrm{C}$ and JNK are known to act as redox-dependent signal molecules (35,37-46). Therefore, deregulation of target molecules by selenium-induced thiol modification may be involved in disrupting various signal transduction pathways that control cell survival and apoptosis.

ROS, which are chemically reactive molecules, including superoxide anions, hydrogen peroxides, hydroxyl radicals, and nitric oxide derivatives, are generated in all aerobic organisms through several pathways as summarized in Fig. 2. The superoxide anion $\left(\mathrm{O}_{2}{ }^{--}\right)$is produced intracellularly by transferring electrons leaked from the electron transport chain in mitochondria and from NADPH cytochrome $\mathrm{P} 450$ reductase in the endoplasmic reticulum to oxygen, as well as by the action of several enzymes including NADPH oxidase, lipooxygenase, cyclooxygenase, flavoenzymes (e.g., xanthine oxidase), and uncoupled nitric oxide synthase (47). In particular, the superoxide anion is also formed endogenously by the reaction of selenium compounds such as selenite, selenium dioxide, diselenides, and selenocysteine, and with thiols such as reduced GSH or L-cysteine $(3,11,48)$. The generation of superoxide anions by selenium has been confirmed by treating cells with exogenous GSH or selenite; this has also been observed by adding isolated mitochondria to selenium-containing compounds, including selenite, selenocysteine, selenocystamine, and selenodioxide, to GSH, or to both $(10,49,50)$. The superoxide anion is rapidly converted to hydrogen peroxide $\left(\mathrm{H}_{2} \mathrm{O}_{2}\right)$ via superoxide dismutase (SOD) followed by the conversion of hydrogen peroxide to a highly reactive hydroxyl radical $\left(\mathrm{HO}^{\circ}\right)$ in the presence of $\mathrm{Fe}^{2+}$ through the Fenton reaction. Subsequently, the hydroxyl radical reacts with $\mathrm{NO}^{\circ}$ to yield the more reactive species $\mathrm{NO}_{2}{ }^{\bullet}$ and $\mathrm{HO}^{\bullet}$ through an $\mathrm{ONOO}^{-}$intermediate. 
Collectively, selenium induces a redox shift toward more oxidizing environments as follows: (i) selenium directly reacts with essential thiols, resulting in thiol oxidation, (ii) serial reductive reactions of selenium with GSH produce superoxide anions after which the superoxide anions generate additional reactive molecules $\left(\mathrm{H}_{2} \mathrm{O}_{2}, \mathrm{HO}^{\circ}, \mathrm{HO}^{-}\right.$, $\mathrm{ONOO}^{-}, \mathrm{NO}_{2}{ }^{\circ}$, and $\mathrm{HO}^{\circ}$ ) via subsequent reactions, such as dismutation and Fenton reaction, and (iii) subsequent reaction of selenium with GSH results in GSH depletion from the export of cellular oxidized GSSG via a transporter. A more oxidizing environment produced by selenium can damage most biomolecules, DNA, proteins, and lipids, thus inducing cellular cytotoxicity.

\section{Selenium-induced apoptosis}

Numerous studies have suggested that selenium might be a preventive and effective anticancer agent for several human cancer cells including those of the prostate, colon, mammary, bladder, lung, liver, ovarian, oral, and blood or bone marrow (51-53). Selenium induces both ROS generation and oxidation, and cross-linking of protein cysteine residues, resulting in impaired protein function and apoptotic cell death. This element also inhibits cancer cell growth and induces cancer cell apoptosis in vitro at molar concentrations known to be toxic. Programmed cell death is marked by cellular morphological changes, including membrane blebbing, nuclear breakdown, chromatin condensation, and formation of apoptotic bodies that are readily eliminated by phagocytosis. This process also initiates activation of caspases, a cystinyl aspartate-specific protease that is stimulated in the process of mitochondrialdependent or -independent apoptosis, and internucleosomal DNA fragmentation (54).

In most cases, apoptosis induced by selenium is associated with typical features commonly observed in cells undergoing this process. Selenium-induced apoptosis in vascular endothelial cells, leukemia HL-60 cells, prostate DU-145 cancer cells, and murine monocytic RAW264.7 cells activates caspase enzymes $(53,55-57)$. DNA fragmentation during the selenium-induced apoptotic process has been reported in various human cancer cell lines including HT29 and SW480 (colonic carcinoma), HepG2 (hepatic carcinoma), A172 and T98G (glioma), and HL-60 (leukemia), as well as the murine monocytic RAW264.7 cell line (57-61). Cells undergoing apoptosis due to selenium occasionally show characteristics of the mitochondrial-mediated apoptotic pathway, such as oxidative damage of mitochondrial protein thiol groups, a decrease in mitochondrial membrane potential, and mitochondrial release of cytochrome $\mathrm{c}$, that can stimulate caspases $(49,50)$. Cyclosporine A, an immunosuppressive mitochondrial membrane permeability transition inhibitor, blocks mitochondrial swelling, and dithiothreitol restored the aggregation between intra- and inter-proteins by crosslinking mitochondrial protein thiol groups and mitochondrial swelling, implying that selenium-induced oxidative stress is involved in mitochondrial dysfunction (62). In summary, selenium-induced apoptosis is accompanied by ROS generation, oxidation of thiol groups in mitochondrial proteins, changes in mitochondrial membrane potential, cytochrome $\mathrm{c}$ release, caspase activation, and DNA fragmentation.

\section{Biological functions of selenium-containing antioxidant proteins}

Normal cellular oxygen metabolism in aerobic organisms leads to the generation of ROS. The disruption of intracellular redox equilibrium results in a state of oxidative stress that can easily damage biologically significant macromolecules. In order to scavenge harmful ROS, aerobic organisms have a wide variety of antioxidant enzymes to protect cells from oxidative stress. Among these, selenoproteins are primarily implicated in maintaining redox homeostasis and reversing apoptotic cell death induced by oxidative stressors, indicating that selenoproteins may act as a safeguard against oxidantinduced toxicity in cells.

Based on bioinformatic data, it has recently been reported that there are 25 selenoproteins in humans and 24 in rodents (63). Selenium is incorporated into these proteins as the 21st amino acid selenocysteine encoded by a UGA codon normally recognized as a stop codon within the mRNA open reading frame. Selenoproteins with known functions include the antioxidants glutathione peroxidase (GPx), thioredoxin reductase (TR), and methionine-R-sulfoxide reductase 1 (MsrB1). These antioxidant selenoproteins serve as central components for the regulation of cellular redox status by maintaining cysteine residues of redox-sensitive proteins in the reduced state and promoting normal cellular functions. GPx catalyzes the reduction of hydrogen peroxide to water by glutathione (4). TR, with a selenocysteine residue in the conserved C-terminal sequence glycine-cysteine-selenocysteine-glycine, is known to reduce thioredoxin by using NADPH and as a result maintains the reduced state of intra cellular proteins $(5,64)$.

MsrB1, in which the active site contains a selenocysteine, contributes to the reduction of methionine sulfoxides in many proteins (25). Together, these enzymes help rescue oxidativelydamaged proteins and perform housekeeping redox functions that allow cells to maintain a favorable intracellular redox status.

\section{Conclusions}

Although it is difficult to determine the difference between beneficial and toxic selenium levels, the current recommended daily intake of selenium to maintain normal cellular functions in adult humans is approximately $100 \mu \mathrm{g}$. Selenium can induce both beneficial and harmful cellular responses, and serves as both an oxidant and antioxidant. A severely selenium-deficient diet leads to oxidative stress due to decreased levels of antioxidant selenoproteins such as GPx, TR, and MsrB1. On the other hand, excessive dietary intake of selenium induces a redox shift towards a more oxidizing cellular environment by directly oxidizing and cross-linking protein thiol groups and indirectly generating oxygen radicals, resulting in apoptotic cell death.

Selenium cytotoxicity is now believed to be caused by oxidative stress. The dual functions of selenium essential for its beneficial antioxidant and toxic pro-oxidant properties make this element useful for decreasing the incidences of selenium-deficiency disorders as well as therapies for treating and preventing cancer. 


\section{Acknowledgements}

This article was supported by a Yeungnam University Research Grant (209-A-380-231).

\section{References}

1. Ge K and Yang G: The epidemiology of selenium deficiency in the etiological study of endemic diseases in China. Am J Clin Nutr 57: 259S-263S, 1993.

2. Tinggi U: Essentiality and toxicity of selenium and its status in Australia: a review. Toxicol Lett 137: 103-110, 2003.

3. Spallholz JE: Free radical generation by selenium compounds and their prooxidant toxicity. Biomed Environ Sci 10: 260-270, 1997.

4. Rotruck JT, Pope AL, Ganther HE, Swanson AB, Hafeman DG and Hoekstra WG: Selenium: biochemical role as a component of glutathione peroxidase. Science 179: 588-590, 1973.

5. Arner ES and Holmgren A: Physiological functions of thioredoxin and thioredoxin reductase. Eur J Biochem 267: 6102-6109, 2000.

6. Moreno-Reyes R, Suetens C, Mathieu F, et al: Kashin-Beck osteoarthropathy in rural Tibet in relation to selenium and iodine status. N Engl J Med 339: 1112-1120, 1998.

7. Gu BQ: Pathology of Keshan disease. A comprehensive review. Chin Med J (Engl) 96: 251-261, 1983.

8. O'Toole D and Raisbeck MF: Pathology of experimentally induced chronic selenosis (alkali disease) in yearling cattle. J Vet Diagn Invest 7: 364-373, 1995.

9. Van Vleet JF and Ferrans VJ: Etiologic factors and pathologic alterations in selenium-vitamin E deficiency and excess in animals and humans. Biol Trace Elem Res 33: 1-21, 1992

10. Yan L and Spallholz JE: Generation of reactive oxygen species from the reaction of selenium compounds with thiols and mammary tumor cells. Biochem Pharmacol 45: 429-437, 1993.

11. Stewart MS, Spallholz JE, Neldner KH and Pence BC: Selenium compounds have disparate abilities to impose oxidative stress and induce apoptosis. Free Radic Biol Med 26: 42-48, 1999.

12. Hoffman DJ: Role of selenium toxicity and oxidative stress in aquatic birds. Aquat Toxicol 57: 11-26, 2002.

13. Allander E: Kashin-Beck disease. An analysis of research and public health activities based on a bibliography 1849-1992. Scand J Rheumatol Suppl 99: 1-36, 1994.

14. Moreno-Reyes R, Mathieu F, Boelaert M, et al: Selenium and iodine supplementation of rural Tibetan children affected by Kashin-Beck osteoarthropathy. Am J Clin Nutr 78: 137-144, 2003.

15. Kempen JH, Mitchell P, Lee KE, et al: The prevalence of refractive errors among adults in the United States, Western Europe, and Australia. Arch Ophthalmol 122: 495-505, 2004.

16. Schubert JR, Muth OH, Oldfield JE and Remmert LF Experimental results with selenium in white muscle disease of lambs and calves. Fed Proc 20: 689-694, 1961

17. Muth OH, Oldfield JE, Remmert LF and Schubert JR: Effects of selenium and vitamin $\mathrm{E}$ on white muscle disease. Science 128: 1090,1958

18. Xu GL, Wang SC, Gu BQ, et al: Further investigation on the role of selenium deficiency in the aetiology and pathogenesis of Keshan disease. Biomed Environ Sci 10: 316-326, 1997.

19. Li GS, Wang F, Kang D and Li C: Keshan disease: an endemic cardiomyopathy in China. Hum Pathol 16: 602-609, 1985.

20. Rayman MP: The importance of selenium to human health. Lancet 356: 233-241, 2000

21. Levander OA and Beck MA: Interacting nutritional and infectious etiologies of Keshan disease. Insights from coxsackie virus B-induced myocarditis in mice deficient in selenium or vitamin E. Biol Trace Elem Res 56: 5-21, 1997.

22. Stone CA, Kawai K, Kupka R and Fawzi WW: Role of selenium in HIV infection. Nutr Rev 68: 671-681, 2010

23. Zhuo P and Diamond AM: Molecular mechanisms by which selenoproteins affect cancer risk and progression. Biochim Biophys Acta 1790: 1546-1554, 2009.

24. Flohe L: Selenium in mammalian spermiogenesis. Biol Chem 388: 987-995, 2007.

25. Kim HY and Gladyshev VN: Methionine sulfoxide reduction in mammals: characterization of methionine-R-sulfoxide reductases. Mol Biol Cell 15: 1055-1064, 2004.

26. Jeong DW, Yoo MH, Kim TS, Kim JH and Kim IY: Protection of mice from allergen-induced asthma by selenite: prevention of eosinophil infiltration by inhibition of NF-kappa B activation. J Biol Chem 277: 17871-17876, 2002.
27. Brozmanova J, Manikova D, Vlckova V and Chovanec M: Selenium: a double-edged sword for defense and offence in cancer. Arch Toxicol 84: 919-938, 2010

28. Yang GQ, Wang SZ, Zhou RH and Sun SZ: Endemic selenium intoxication of humans in China. Am J Clin Nutr 37: 872-881, 1983.

29. Ruta DA and Haider S: Attempted murder by selenium poisoning. BMJ 299: 316-317, 1989.

30. Vinceti M, Wei ET, Malagoli C, Bergomi M and Vivoli G: Adverse health effects of selenium in humans. Rev Environ Health 16: 233-251,2001.

31. Goehring TB, Palmer IS, Olson OE, Libal GW and Wahlstrom RC: Toxic effects of selenium on growing swine fed corn-soybean meal diets. J Anim Sci 59: 733-737, 1984.

32. Lopez S, Miyashita Y and Simons SS Jr: Structurally based, selective interaction of arsenite with steroid receptors. J Biol Chem 265: 16039-16042, 1990.

33. Frenkel GD, Walcott A and Middleton C: Inhibition of RNA and DNA polymerases by the product of the reaction of selenite with sulfhydryl compounds. Mol Pharmacol 31: 112-116, 1987.

34. Ganther HE: Selenium metabolism, selenoproteins and mechanisms of cancer prevention: complexities with thioredoxin reductase. Carcinogenesis 20: 1657-1666, 1999.

35. Kim IY and Stadtman TC: Inhibition of NF- $\kappa B$ DNA binding and nitric oxide induction in human $\mathrm{T}$ cells and lung adenocarcinoma cells by selenite treatment. Proc Natl Acad Sci USA 94: 12904-12907, 1997.

36. Spyrou G, Bjornstedt M, Kumar S and Holmgren A AP-1 DNA-binding activity is inhibited by selenite and selenodiglutathione. FEBS Lett 368: 59-63, 1995.

37. Kim JY, Park HS, Kang SI, Choi EJ and Kim IY: Redox regulation of cytosolic glycerol-3-phosphate dehydrogenase: Cys(102) is the target of the redox control and essential for the catalytic activity. Biochim Biophys Acta 1569: 67-74, 2002.

38. Ghosh J: Rapid induction of apoptosis in prostate cancer cells by selenium: reversal by metabolites of arachidonate 5-lipoxygenase. Biochem Biophys Res Commun 315: 624-635, 2004.

39. Bergad PL and Rathbun WB: Inhibition of $\mathrm{Na}, \mathrm{K}-\mathrm{ATPase}$ by sodium selenite and reversal by glutathione. Curr Eye Res 5: 919-923, 1986

40. Tashima Y, Terui M, Itoh H, Mizunuma H, Kobayashi R and Marumo F: Effect of selenite on glucocorticoid receptor. J Biochem 105: 358-361, 1989.

41. Islam F, Watanabe $\mathrm{Y}$, Morii $\mathrm{H}$ and Hayaishi O: Inhibition of rat brain prostaglandin $\mathrm{D}$ synthase by inorganic selenocompounds. Arch Biochem Biophys 289: 161-166, 1991.

42. Sinha R and Medina D: Inhibition of cdk2 kinase activity by methylselenocysteine in synchronized mouse mammary epithelial tumor cells. Carcinogenesis 18: 1541-1547, 1997.

43. Gopalakrishna R, Chen ZH and Gundimeda U: Selenocompounds induce a redox modulation of protein kinase $\mathrm{C}$ in the cell, compartmentally independent from cytosolic glutathione: its role in inhibition of tumor promotion. Arch Biochem Biophys 348: 37-48, 1997.

44. Handel ML, Watts CK, deFazio A, Day RO and Sutherland RL: Inhibition of AP-1 binding and transcription by gold and selenium involving conserved cysteine residues in Jun and Fos. Proc Natl Acad Sci USA 92: 4497-4501, 1995.

45. Park HS, Huh SH, Kim Y, et al: Selenite negatively regulates caspase-3 through a redox mechanism. J Biol Chem 275 8487-8491, 2000.

46. Park HS, Park E, Kim MS, Ahn K, Kim IY and Choi EJ: Selenite inhibits the c-Jun N-terminal kinase/stress-activated protein kinase (JNK/SAPK) through a thiol redox mechanism. J Biol Chem 275: 2527-2531, 2000.

47. Kulkarni AC, Kuppusamy P and Parinandi N: Oxygen, the lead actor in the pathophysiologic drama: enactment of the trinity of normoxia, hypoxia, and hyperoxia in disease and therapy. Antioxid Redox Signal 9: 1717-1730, 2007.

48. Shen HM, Yang CF and Ong CN: Sodium selenite-induced oxidative stress and apoptosis in human hepatoma HepG2 cells. Int J Cancer 81: 820-828, 1999.

49. Kim TS, Jeong DW, Yun BY and Kim IY: Dysfunction of rat liver mitochondria by selenite: induction of mitochondrial permeability transition through thiol-oxidation. Biochem Biophys Res Commun 294: 1130-1137, 2002.

50. Kim TS, Yun BY and Kim IY: Induction of the mitochondrial permeability transition by selenium compounds mediated by oxidation of the protein thiol groups and generation of the superoxide. Biochem Pharmacol 66: 2301-2311, 2003. 
51. Sanmartin C, Plano D and Palop JA: Selenium compounds and apoptotic modulation: a new perspective in cancer therapy. Mini Rev Med Chem 8: 1020-1031, 2008.

52. Clark LC, Combs GF, Jr., Turnbull BW, et al: Effects of selenium supplementation for cancer prevention in patients with carcinoma of the skin. A randomized controlled trial. Nutritional Prevention of Cancer Study Group. JAMA 276: 1957-1963, 1996.

53. Jiang C, Wang Z, Ganther $\mathrm{H}$ and Lu J: Caspases as key executors of methyl selenium-induced apoptosis (anoikis) of DU-145 prostate cancer cells. Cancer Res 61: 3062-3070, 2001.

54. Pradelli LA, Beneteau M and Ricci JE: Mitochondrial control of caspase-dependent and -independent cell death. Cell Mol Life Sci 67: 1589-1597, 2010

55. Jiang C, Kim KH, Wang Z and Lu J: Methyl selenium-induced vascular endothelial apoptosis is executed by caspases and principally mediated by p38 MAPK pathway. Nutr Cancer 49: 174-183, 2004.

56. Kim T, Jung U, Cho DY and Chung AS: Se-methylselenocysteine induces apoptosis through caspase activation in HL-60 cells. Carcinogenesis 22: 559-565, 2001

57. Chung YW, Kim TS, Lee SY, et al: Selenite-induced apoptosis of osteoclasts mediated by the mitochondrial pathway. Toxicol Lett 160: 143-150, 2006.

58. Cho DY, Jung U and Chung AS: Induction of apoptosis by selenite and selenodiglutathione in HL-60 cells: correlation with cytotoxicity. Biochem Mol Biol Int 47: 781-793, 1999.
59. Zhu Z, Jiang W, Ganther HE, Ip C and Thompson HJ: In vitro effects of Se-allylselenocysteine and Se-propylselenocysteine on cell growth, DNA integrity, and apoptosis. Biochem Pharmacol 60: 1467-1473, 2000.

60. Stewart MS, Davis RL, Walsh LP and Pence BC: Induction of differentiation and apoptosis by sodium selenite in human colonic carcinoma cells (HT29). Cancer Lett 117: 35-40, 1997.

61. Zhu Z, Kimura M, Itokawa Y, et al: Apoptosis induced by selenium in human glioma cell lines. Biol Trace Elem Res 54: 123-134, 1996

62. Petronilli V, Costantini P, Scorrano L, Colonna R, Passamonti S and Bernardi P: The voltage sensor of the mitochondrial permeability transition pore is tuned by the oxidation-reduction state of vicinal thiols. Increase of the gating potential by oxidants and its reversal by reducing agents. J Biol Chem 269: 16638-16642, 1994.

63. Kryukov GV, Castellano S, Novoselov SV, et al: Characterization of mammalian selenoproteomes. Science 300: 1439-1443, 2003.

64. Holmgren A and Lu J: Thioredoxin and thioredoxin reductase: current research with special reference to human disease. Biochem Biophys Res Commun 396: 120-124, 2010 